\title{
Modificacions al recorregut de recerca geològica i mineralògica per la comarca del Pallars Jussà: des d'Espui, cap al Coll de Triador, la Cambra d'Aigües, I'Estany Gento, I'Estany Tort i cap al Refugi de Colomina
}

Josep Maria Mata-Perelló

Joaquim Sanz Balagué

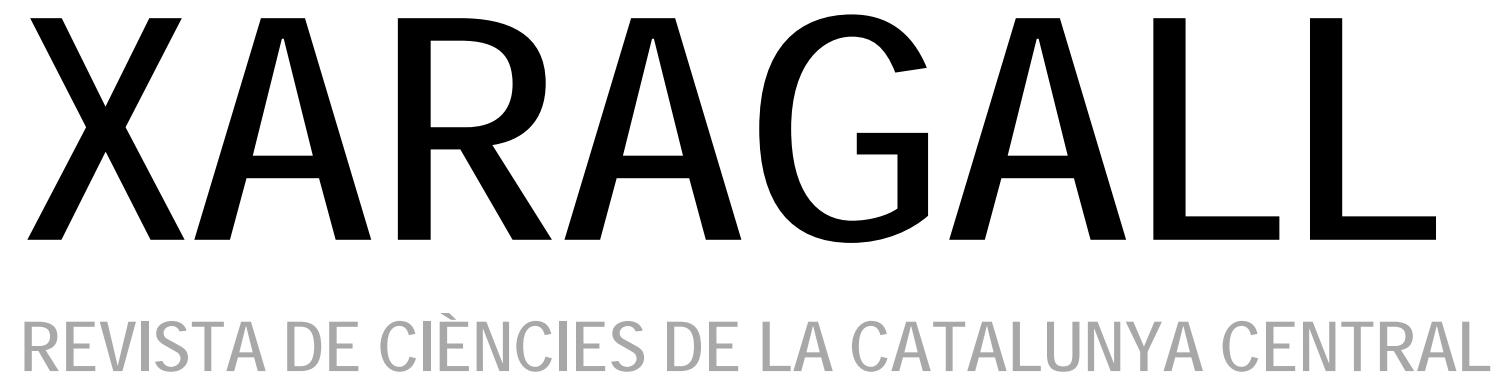

n. 8

AGOST 2014

Com citar l'article: Mata-Perelló, JM.; Sanz Balaguer, J. Modificacions al recorregut de recerca geològica i mineralògica per la comarca del Pallars Jussà: des d’Espui, cap al Coll de Triador, la Cambra d’Aigües, I'Estany Gento, I'Estany Tort i cap al Refugi de Colomina. A: XARAGALL. Revista de Ciències de la Catalunya Central. 2014. (n.8). ISSN 2013-4479 DL: B.21483-2009. DOI 


\title{
MODIFICACIONS AL RECORREGUT DE RECERCA GEOLÒGICA I MINERALÒGICA PER LA COMARCA DEL PALLARS JUSSÀ: DES D'ESPUI, CAP AL COLL DE TRIADOR, LA CAMBRA D'AIGÜES, L'ESTANY GENTO, L'ESTANY TORT I CAP AL REFUGI DE COLOMINA
}

\author{
Josep Maria Mata-Perelló \\ Museu de geologia Valentí Masachs, Escola Politècnica Superior d'Enginyeria de Manresa \\ (EPSEM), Universitat Politècnica de Catalunya · BarcelonaTech (UPC), 08272 Manresa, Spain
}

\section{Joaquim Sanz Balagué}

Departament d'Enginyeria Minera i Recursos Naturals (EMRN), Escola Politècnica Superior d'Enginyeria de Manresa (EPSEM), Universitat Politècnica de Catalunya - BarcelonaTech (UPC), 08272 Manresa, Spain

Paraules clau: Sistema Pirinenc; Zona Axial Pirinenca; Unitat de les Nogueres; Materials paleozoics; Patrimoni miner

\section{Resum}

Itinerari realitzat el 21 de setembre de 2013. En aquesta ocasió, la totalitat del recorregut de l'itinerari es desenvoluparà per una sola unitat geològica: concretament pel Sistema Pirinenc, i més exactament per la zona de contacte entre la Unitat de les Nogueres i la Zona Axial Pirinenca, situada al nord de l'anterior. D'aquesta manera, el recorregut s'iniciarà a la població d’Espui (del terme de la Torre de Cabdella), situada a la Unitat de les Nogueres.

Així, a partir d'aquí l'itinerari transitarà per aquesta unitat acabada d'esmentar, anant cap a I'Estany Gento. Més amunt, en arribar-hi, es trobarà el contacte amb la Zona Axial Pirinenca, que ja no s'abandonarà en tota la resta del recorregut.

Així, inicialment, s'aniran trobant afloraments dels materials paleozoics del Silurià i del Devonià. Més endavant, en arribar a la Zona Axial, es trobaran granits i granodiorites carboníferes., així com afloraments paleozoics de I'Ordovicià, Silurià i Devonià, fonamentalment. 


\section{Objectius fonamentals}

Es centraran en els aspectes geològics, geomorfològics i mineralògics que apuntarem a continuació:

1. Observació dels materials que constitueixen la Unitat de les Nogueres, que anirem trobant entre Espui i les immediacions de l'Estany Gento. Aquests materials pertanyen, en aquest tram, exclusivament al paleozoic (repartint-se entre el Carbonífer, el Devonià i el Silurià). Així, trobarem afloraments del Carbonífer (amb trams d'esquistos negres, fonamentalment), del Devonià (amb trams de calcàries) i del Silurià (amb pissarres negres, molt grafitoses i piritoses).

2. Observació dels materials que constitueixen la Zona Axial Pirinenca, que anirem trobant entre les immediacions de l’Estany Gento i la fi del recorregut. Aquests materials pertanyen, exclusivament al paleozoic (repartint-se entre el Carbonífer, el Devonià, el Silurià i l'Ordovicià). Així, trobarem afloraments de l'Ordovicià (amb trams d'esquistos, fonamentalment), del Silurià (amb pissarres negres, molt grafitoses i piritoses), del Devonià (amb trams de calcàries ) i del Carbonífer (amb granits i granodiorites).

3. Observació de les relacions existents entre les dues subunitats pirinenques acabades d'esmentar.

4. Observació de les diferents mineralitzacions que anirem trobant al llarg del recorregut, si es dona el cas.

5. Observació al llarg del recorregut de l'itinerari de les antigues explotacions situades al llarg del recorregut.

6. Observació de l’impacte produït sobre el Medi Natural, tant de la mineria com a conseqüència de les obres efectuades per la zona.

7. Observació dels diferents aspectes relacionats amb el glacialisme i amb el periglacialisme, que anirem veient al llarg de tot el recorregut del present itinerari.

8. Observació dels indrets relacionats amb el patrimoni geològic, que es vagi trobant al llarg del recorregut. Aquí,, cal fer esment del relacionat amb l’apartat anterior.

9. Observació dels indrets relacionats amb el patrimoni miner, que es vagi trobant al llarg del recorregut. Aquí, fent una certa extrapolació, podríem parlar del relacionat amb l'aprofitament de les aigües superficial per part de les industries elèctriques.

\section{Antecedents}

Pel que fa al recorregut del present itinerari, existeix alguns antecedents nostres. Es tracta de Mata-Perelló (2013a, 2013b i 2013c, aquest darrer és el que ara modifiquem i ampliem). Tret d'aquests, cal fer esment d'un important treball (Martínez 2013), amb un recull d'itineraris geològics pel Parc Nacional d'Aigües Tortes i de Sant Maurici.

Pel que fa a la descripció de les mineralitzacions, cal parlar d'un altre treball, també nostre; en concret de Mata-Perelló (1991). Aquest treball es relatiu a les mineralitzacions catalanes en general, amb un capítol dedicat a la Noguera. També cal fer esment de Mata-Perelló i Sanz (1993), dedicat al reconeixement dels minerals.

Xaragall.2014 n.8 | Modificacions al recorregut de recerca geològica i mineralògica per la comarca del Pallars 
I pel que fa a l'estructura geològica de la zona per la qual discorre l'itinerari, farem esment de dos treballs, molt interessants, de caràcter generalista. En concret, ens estem referint als següents: Guimerà et altri (1982). i també a Riba et altri (1976). Tots dos treballs es refereixen a la geologia dels Països Catalans, i conseqüentment de Catalunya. Per d'altra banda, també cal fer esment del treball de Rosell (1970); així com de I'IGME (1994).

Tots aquests treballs referenciats, i d'altres, figuren esmentats per ordre alfabètic a l'apartat dedicat a la BIBLIOGRAFIA.

\section{Recorregut de l'itinerari}

El recorregut de l'itinerari discorrerà per una comarca de la Regió de Tremp - la Seu d'Urgell; concretament per la del Pallars Jussà i dintre d'aquesta per la Vall Fosca, en els seu tram superior. Així, el recorregut s'iniciarà a la població d'Espui, situada a la Vall del Flamisell, situada sobre la carretera local $L-503$. A partir d'aquesta població, ens caldrà pujar cap a les immediacions del Coll de Triadors, tot seguint una pista. Cal dir que aquest recorregut I'efectuarem dintre del Mantell de la Zona de les Nogueres.

Després. es caldrà continuar a peu, tot seguint l'antic recorregut del ferrocarril que s'adreça fins a l'Estany Gento, sortint des de la Cambra d'Aigües En aquest recorregut, haurem transitat pel Mantell de les Nogueres. Posteriorment, poc abans d'arribar a I'Estany Gento, haurem entrat a la Zona Axial Pirinenca, que ja no abandonarem.

Des d'aquí, el recorregut es dirigirà cap a l'Estany Tort i cap al Refugi de Colomina, per on finalitzarà el recorregut de I'itinerari. Al llarg de tot aquest recorregut, $\mathrm{s}^{\prime}$ aniran fent diverses aturades, sense abandonar la Zona Axial Pirinenca.

\section{Advertiments previs}

Com en altres recorreguts de RECERCA GEOLÒGICA I MINERALÒGICA... si es disposa del temps suficient, poden efectuar-se passant per totes les parades i filloles. En cas contrari, recomanem prescindir de les anomenades PARADES - CONDICIONALS.

També cal tenir en conte que una part del recorregut de l'itinerari, es realitzarà per camins de terra, per la qual cosa caldrà prendre les degudes precaucions. Per d'altra banda, una bona part del recorregut es realitzarà a peu, tot anant des del Coll de Triador, fins a I'Estany Gento, I'Estany Tort i fins al Refugi de Colomines

Cal tenir, com sempre, una cura molt especial de respecte a la natura, al llarg de tot el recorregut de l'itinerari, i també fora d'ell. 


\section{Descripció de l'itinerari}

En aquest recorregut hem situat, com ja és habitual en tots els itineraris, una sèrie d'ESTACIONS o de PARADES, que anirem veient a continuació. En cada cas, els hi donarem una denominació que podrà correspondre a algun paratge proper. També indicarem el terme municipal i la comarca on es troba.

Per d'altra banda, en cada una de les parades, indicarem entre parèntesi el número del "Mapa Topográfico", a escala 1:50.000, on es troba situada la parada considerada. En aquesta ocasió serà algun dels següents: 181 (o d'Esterri d'Áneu) i 214 (o de Sort). També es farà servir el full $n^{\circ} 54$ (Vall Fosca) del Mapa topogràfic de Catalunya, del ICC. Així doncs, la relació ordenada de les parades que composen aquest recorregut, és la següent.

\subsection{Parada 1. INICI DEL CAMÍ D’ESPUI CAP EL COLL DE TRIADOR, (Espui, terme municipal de la Torre de Cabdella, la Vall Fosca, comarca del Pallars Jussà). (Fulls 214 i 54).}

El recorregut d'aquest itinerari, el començarem a la població d’Espui, situada al bell mig de la vall, aigües amunt de la seva capital administrativa, la població de la Torre de Cabdella. Així, I'iniciarem el recorregut, al començament del camí - pista que es dirigeix cap a llevant, per tal d'arribar fins a les immediacions del Coll de Triador.

La població d'Espui, es troba situada dintre del Sistema Pirinenc, on es troba també tota la Vall Fosca. Tot i així, aquests sectors es troben situats dintre de a Unitat del Mantell de les Nogueres, però molt a prop de la Zona Axial Pirinenca. Així, per arreu, es veuen afloraments dels materials paleozoics del Devonià.

Efectivament, per aquests indrets predominen els terrenys eminentment carbonatats del Devonià. Es fàcil veure trams del Devonià Mig (amb calcàries de la Formació Manyanet i pissarres de la Formació Vilaller); i també trams més propers del Devonià Inferior (amb pissarres i calcaries de la Formació Basibé i amb pissarres i calcaries de la Formació Rueda). Tot $i$ així, molt sovint, aquests materials es troben recoberts per terrenys neògens, del Pleistocè i de l'Holocè, d'origen glacial i fluvial, segons els indrets.

Des d'aquest indret, prop del pont sobre el Noguera de Flamisell, es pot veure la morfologia glacial d'aquesta vall. 


\subsection{Parada 2. PRIMERS TRAMS DEL CAMÍ D’ESPUI CAP EL COLL DE TRIADOR, (Espui, terme municipal de la Torre de Cabdella, la Vall Fosca, comarca del Pallars Jussà). (Fulls 214 i 54).}

Després d'iniciar el camí cap el Coll de Triador, trobarem un tram que no puja gaire, però ben aviat començarem a pujar, fent revolts. Quasi al començament, després fer dos o tres revolts, podem fer una nova aturada.

En aquest recorregut, haurem trobat els materials esmentats anteriorment. Tot i així, en una bona part del trajecte, els veurem recoberts per derrubis de pendent de l'Holocè. També, com a I'indret de l'aturada, podem veure uns depòsits d'origen glacial, d'aspecte morrènic. Tot i això veure uns grans blocs (de granodiorites, fonamentalment, arrossegades pel glacial des de la capçalera de la vall). Aquests blocs els veurem envoltats de depòsits detrítics de gra fi, fonamentalment de sorres (també de procedència glacial). Es tracta possiblement d'uns Tills, d'uns dipòsits d'origen glacial del Pleistocè, Tot i que es troben barrejats amb derrubis de pendent. (fotografia 1 ).

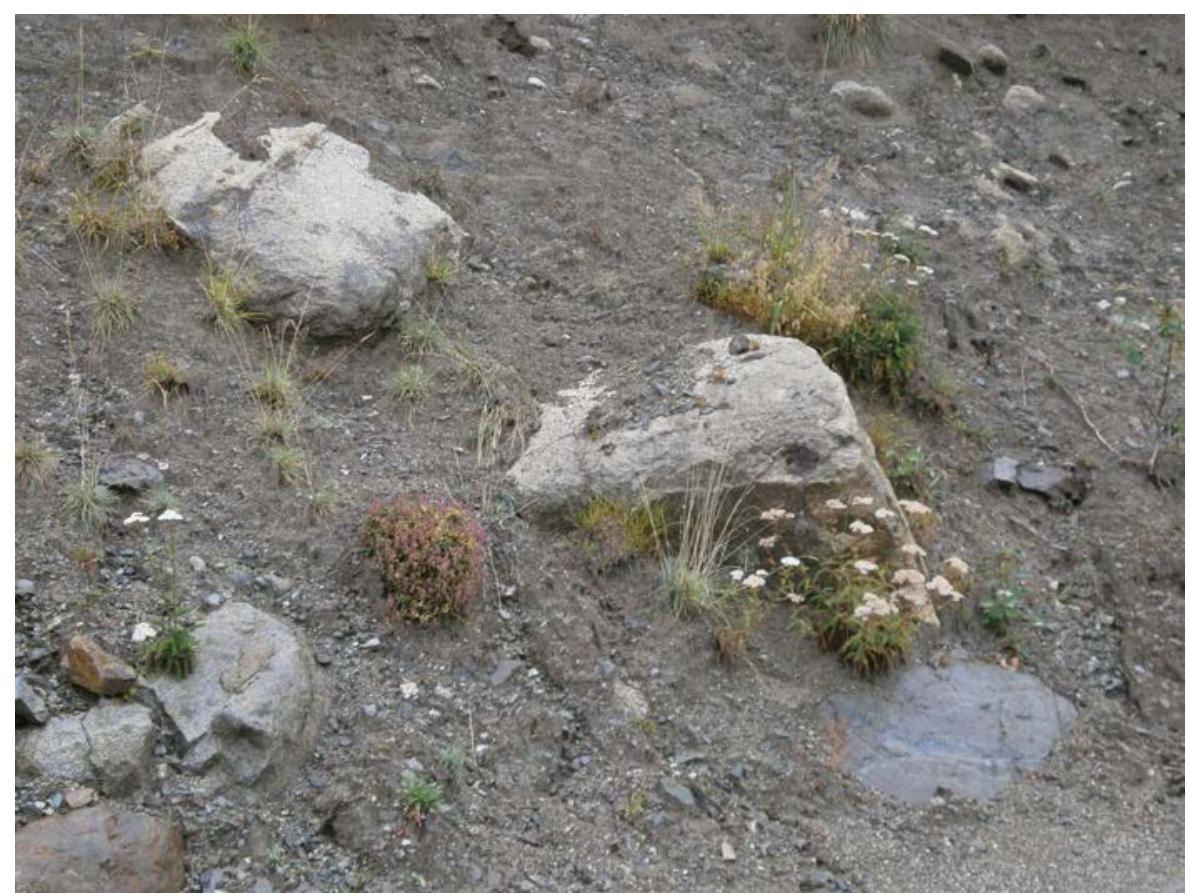

Fotografia 1. Un aspecte dels depòsits glacials (Tills) barrejats amb deòsits gravitacionals (derrubis de pendets). Camí d’Espui al Coll de Triador.Setembre 2013

Xaragall.2014 n.8 | Modificacions al recorregut de recerca geològica i mineralògica per la comarca del Pallars Jussà: des d’Espui, cap al Coll de Triador, la Cambra d'Aigües, I’Estany Gento, I'Estany Tort i cap al Refugi de 


\subsection{Parada 3. TRAMS INTERMITJOS DEL CAMÍ D’ESPUI CAP EL COLL DE TRIADOR, (Espui, terme municipal de la Torre de Cabdella, la Vall Fosca, comarca del Pallars Jussà). (Fulls 214 i 54).}

Després de fer l'aturada anterior, cal continuar ascendint cap el Coll de Triador, pel camí que hem agafat a la sortida d'Espui. Aquest camí va ascendint molt ràpidament, entre afloraments dels materials del Pleistocè i de l'Holocè, els quals cobreixen als paleozoics del Silurià, per entre els quals anem ara circulant.

Després d'uns $4-5 \mathrm{Km}$, veurem uns plecs molt interessants, situats entre els materials del Silurià. Aquest es troben en una sèrie de revolts molt pronunciats, per on discorre el camí ascendent. (fotografia 2).

Tanmateix, mirant cap al SE, veurem interesants estructures periglacials, com els coneguts camins de vaques, que consisteixen en fenòmens de solifluxió.

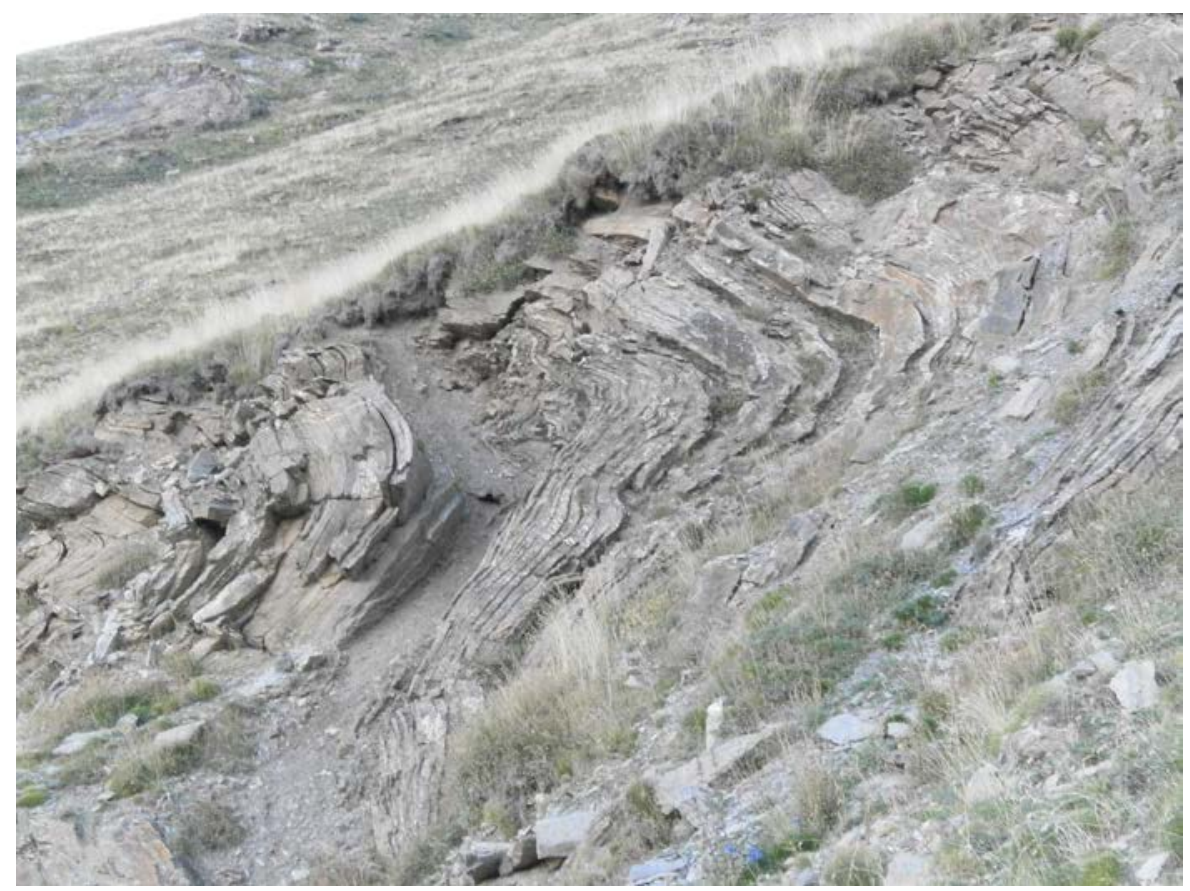

Fotografia 2. Un aspecte dels plecs i replecs entre els matetrials pissarrencs del Siluria. Camí d’Espui al Coll de Triador.Setembre 2013

Xaragall.2014 n.8 | Modificacions al recorregut de recerca geològica i mineralògica per la comarca del Pallars 


\subsection{Parada 4 - CONDICIONAL. IMMEDIACIONS DEL COLL DEL TRIADOR, (Espui i Llessui, termes municipal de la Torre de Cabdella i de Sort, comarques del Pallars Jussà i del Pallars Sobirà, respectivament). (Fulls 214 i 54).}

Des de la parada anterior, cal acabar d'arribar fins al Coll de Triador, pujant sempre per la vorera occidental del Montsent de Pallars. En arribar a les immediacions del Coll de Triador, farem una nova aturada, després d'un recorregut proper als $3-4 \mathrm{Km}$, des de la parada anterior. En arribar a aquest indret, haurem trobat (ben prop d'on ara som) la cruïlla amb els camins de muntanya que es dirigeixen cap a Llessui i cap a Espot, del Pallars Sobirà. És a dir, hem arribar al límit del Pallars Jussà amb l'esmentat Pallars Sobirà.

En aquest recorregut, sempre ascendent, haurem trobat afloraments dels diferents materials que formen part dels materials paleozoics del Mantell de les Nogueres, on ens trobem situats. Així, haurem vist afloraments dels materials paleozoics (primer del Devonià, i després del Silurià i de l'Ordovicià). Tot i així, des de bona part del recorregut, haurem anant trobant els materials del Silurià, com a l'indret on ara som.

Tot i això, aquests materials es troben recoberts, molt sovint per terrenys detrítics cenozoics, neògens (del Pleistocè i de l'Holocè), d'origen generalment glacial o fluvial, segons els indrets. Així, sovint, haurem trobat afloraments de les morrenes glacials per tot arreu, procedents del glacial de la Vall Fosca.

\subsection{Parada 5. CÀMARA d’AIGÚES DE LA CENTRAL DE CABDELLA, (Cabdella, terme municipal de la Torre de Cabdella, la Vall Fosca, comarca del Pallars Jussà). (Fulls 214 i 54).}

Des de la parada anterior, cal continuar pel camí - pista que ara es dirigeix cap el Nord, sense travessar el Coll de Triador. Per aquest camí s'arriba a una cabana de pastors i tot seguit baixa cap a la propera Cambra d'Aigües. En arribar a aquest indret, farem unes nova aturada, a menys de $1 \mathrm{Km}$ de la parada anterior.

En aquest recorregut, haurem trobat afloraments dels materials paleozoics del Silurià, ja esmentats a les aturades anteriors. Aquests són també els materials que apareixen a l'indret de la present aturada.

Fins aquest indret arribava el canal d'aigües, des de l'Estany Gento, soterrat a la muntanya. A partir d'aquí baixava per dues canonades cap a la Central Hidroelèctrica de Cabdella, la qual es troba situada a la vall, entre les poblacions de Cabdella i d'Espui.

També hi ha les restes d'un funicular, que comunicava Cabdella amb la Estació Intermitja; i aquesta amb la Cambra d'Aigües on estem ara situats. Fins a cert punt, es pot considerar com a un tipus de Patrimoni Miner; ja que la mineria es I'aprofitament dels recursos geològics i I'aigua n'és un d'ells. (fotografia 3). 


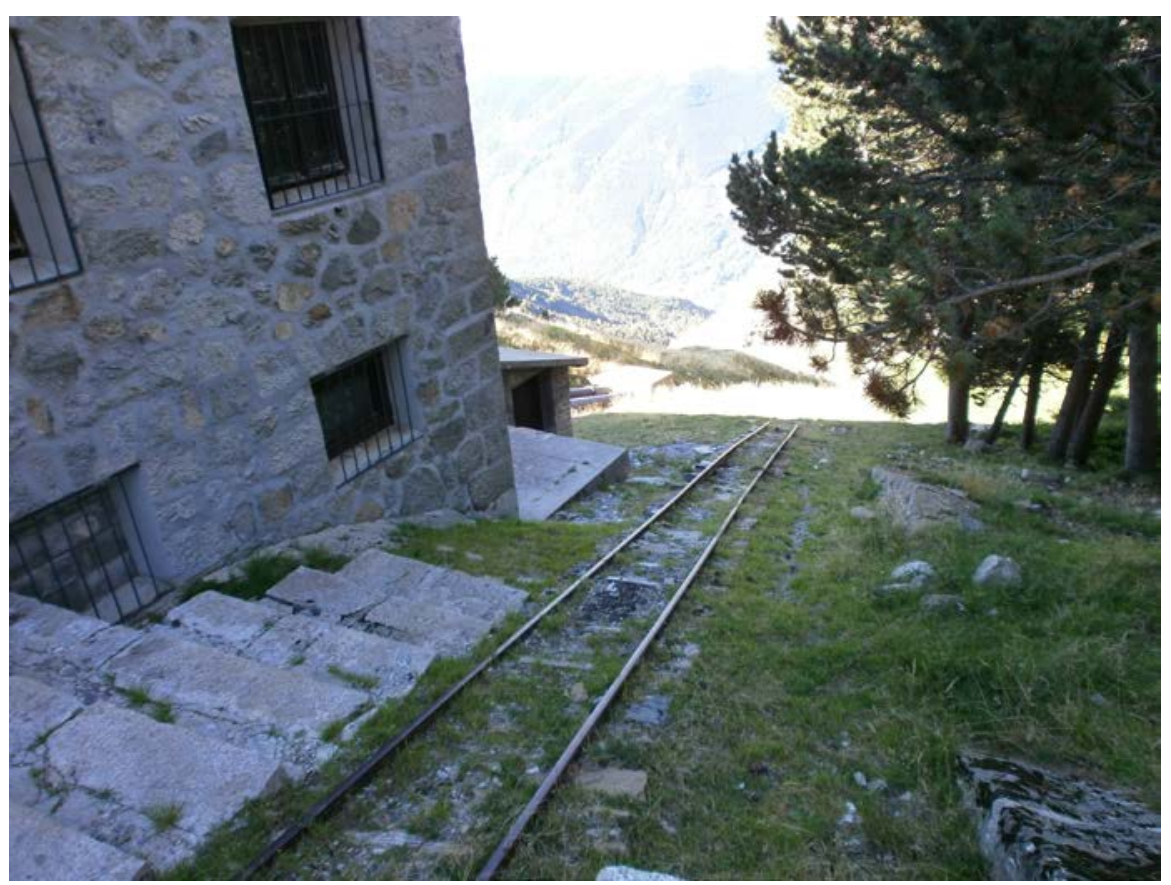

Fotografia 3. Restes del funicular hidroelèctric de Cabdella, un exemple del patrimoni miner sovint no considerat com a tal.Setembre 2013

\subsection{Parada 6. BARRANC DE CUIROLA, (Cabdella, terme municipal de la Torre de Cabdella, la Vall Fosca, comarca del Pallars Jussà). (Fulls 214 i 54).}

Des de la parada anterior, cal continuar a peu, tot seguint l'antic carrilet que anava cap a l'Estany Gento. A poc més de $1-1^{\prime} 5 \mathrm{Km}$, arribarem a les immediacions del Barranc de Cuirola, que baixa des del Montsent de Pallars. Aquí, podem fer una nova aturada.

En aquest recorregut, hem continuat trobant els materials esmentats a l'aturada anterior, els nivells pissarrencs del Silurià. Aquests són també els materials que es troben a l'indret de la present aturada. Per d'altra banda, per sobre nostre, es fan clarament palesos els afloraments dels materials carbonatats del Devonià. Aquests formen part dels relleus del Montsent de Pallars, situats a I’Est del vial que anem seguint.

També hem trobat per arreu, afloraments dels materials detrítics d'origen glacial, molt heteromètrics, formen part de les antigues morrenes. Aquests materials del Pleistocè i de l'Holocè, cobreixen a tots els anteriors.

Des d'aquest indret, mirant cap a ponent, es pot veure la Vall de Filià. Es tracta d'una interessant vall glacial penjada, afluent de I'arteria glacial principal, que passava per I'actual Vall Fosca. Efectivament, cal considerar que per aquesta vall lateral, situada per sobre d’Espui, corria un glacial, tributari del que seguia la Vall Fosca. (fotografia 4). I tanmateix, també es veu be la Ribera de Rigüerna, amb el Circ de Rus, per on baixava un altre glacial afluent. (fotografía 5).

Xaragall.2014 n.8 | Modificacions al recorregut de recerca geològica i mineralògica per la comarca del Pallars Jussà: des d’Espui, cap al Coll de Triador, la Cambra d'Aigües, I’Estany Gento, I'Estany Tort i cap al Refugi de 


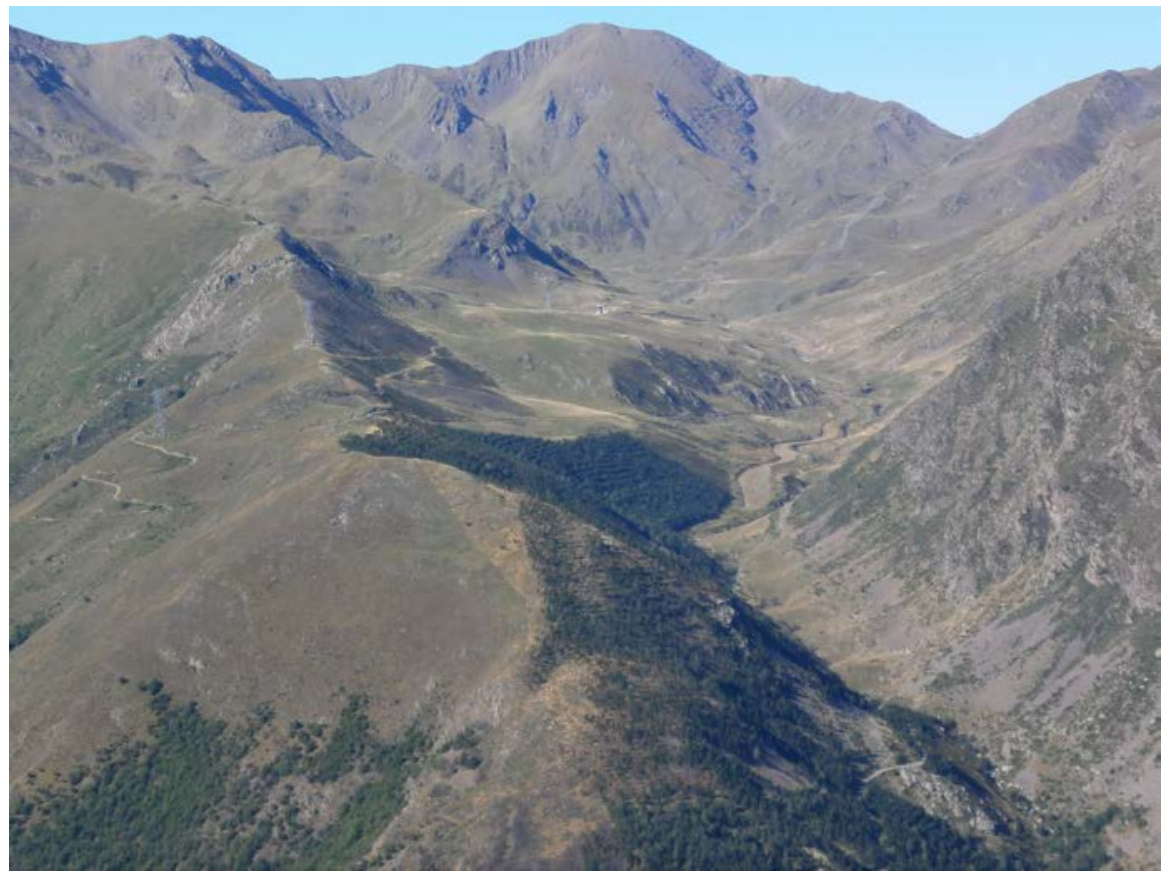

Fotografia 4. Un aspecte de la Vall de Filià, amb el Circ de Filià i el Pic de Filià Setembre 2013

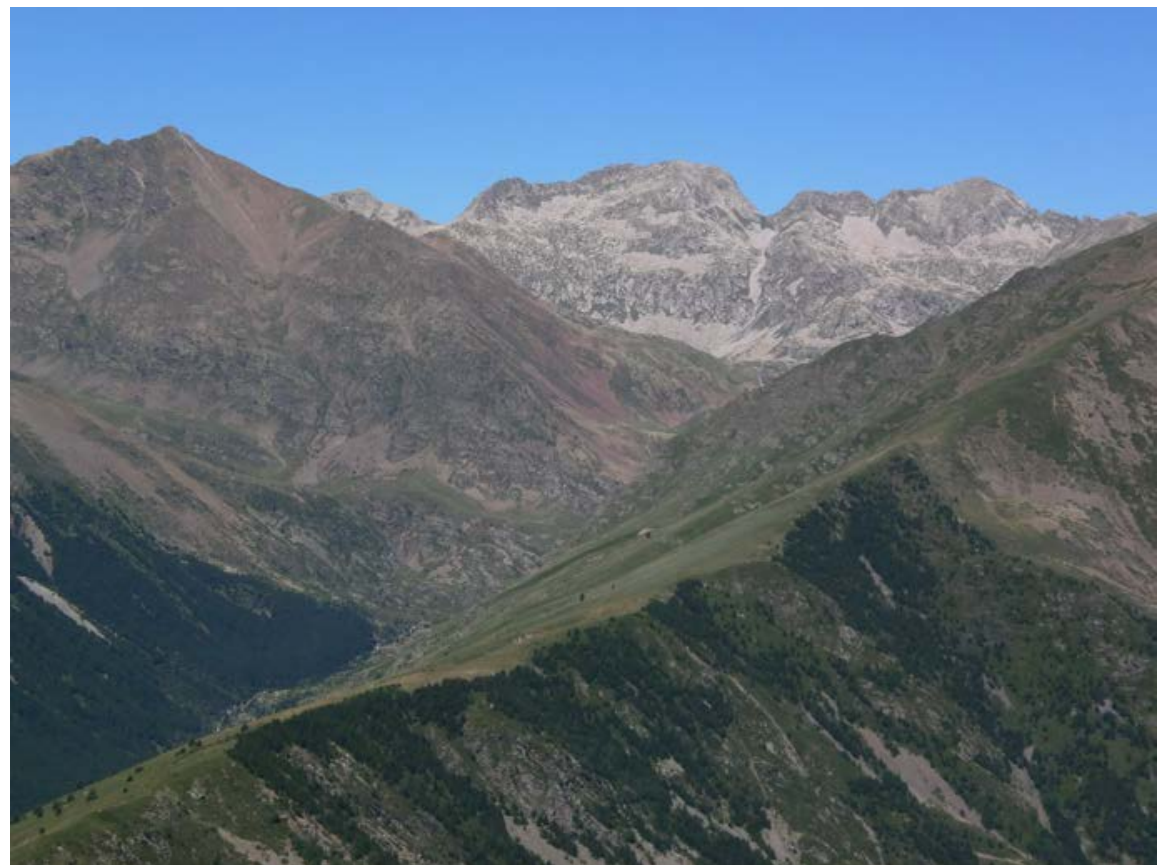

Fotografia 5. Un aspecte de la Ribera de Rigüerna, sm el Circ de Rus. Es veu el contacte, entre els materials de I'Ordovicià i els granits carbonífers. Agost 2013

Xaragall.2014 n.8 | Modificacions al recorregut de recerca geològica i mineralògica per la comarca del Pallars Jussà: des d’Espui, cap al Coll de Triador, la Cambra d'Aigües, I'Estany Gento, l'Estany Tort i cap al Refugi de 


\subsection{Parada 7. BARRANC DE VALLDOMARS, IMMEDIACIONS DE LA PALA DE LA RODA, (Cabdella, terme municipal de la Torre de Cabdella, la Vall Fosca, comarca del Pallars Jussà). (Fulls 181 i 54).}

Després de realitzar la parada anterior, cal continuar per la plataforma de l'antic ferrocarril, que es va apropant cap a l'Estany Gento. A poc més de 1'5 - $2 \mathrm{Km}$ de la parada anterior, per les immediacions de la Pala de la Roda, després d'haver saturat el Barranc de Valldomars, podem fer una nova aturada.

En aquest tram, el camí va seguint un suau ascens, sempre per la vessant occidental del impressionant Monsent de Pallars, que queda a la nostra dreta. Mentre, a la nostra esquerra queda molt palesa la Vall Fosca.

En aquest recorregut, molt sovint haurem trobat afloraments dels materials carbonatats del Devonià (tot formant par de I'Encavalcament del Montsent), aquests nivells carbonatats sovint es troben fracturats.

Per d'altra banda, tanmateix, haurem trobat afloraments dels nivells pissarrencs del Silurià, de tonalitats molt fosques, sovint negres. Cal dir que aquests materials es troben generalment força replegats.

Des de l'indret de la present aturada, es pot fer una bona observació de la Vall Fosc, observant-se per arreu el seu aspecte glacial, amb una vall en forma de "U". Efectivament, era ocupada per un glacial. Tanmateix, a dreta i a esquerra, es poden veure diferents valls penjades, corresponents a antics glacials tributaris (com els que hem esmentat a la parada anterior: la Vall de Filià i la Ribera de Rigüerna). (fotografia 6).

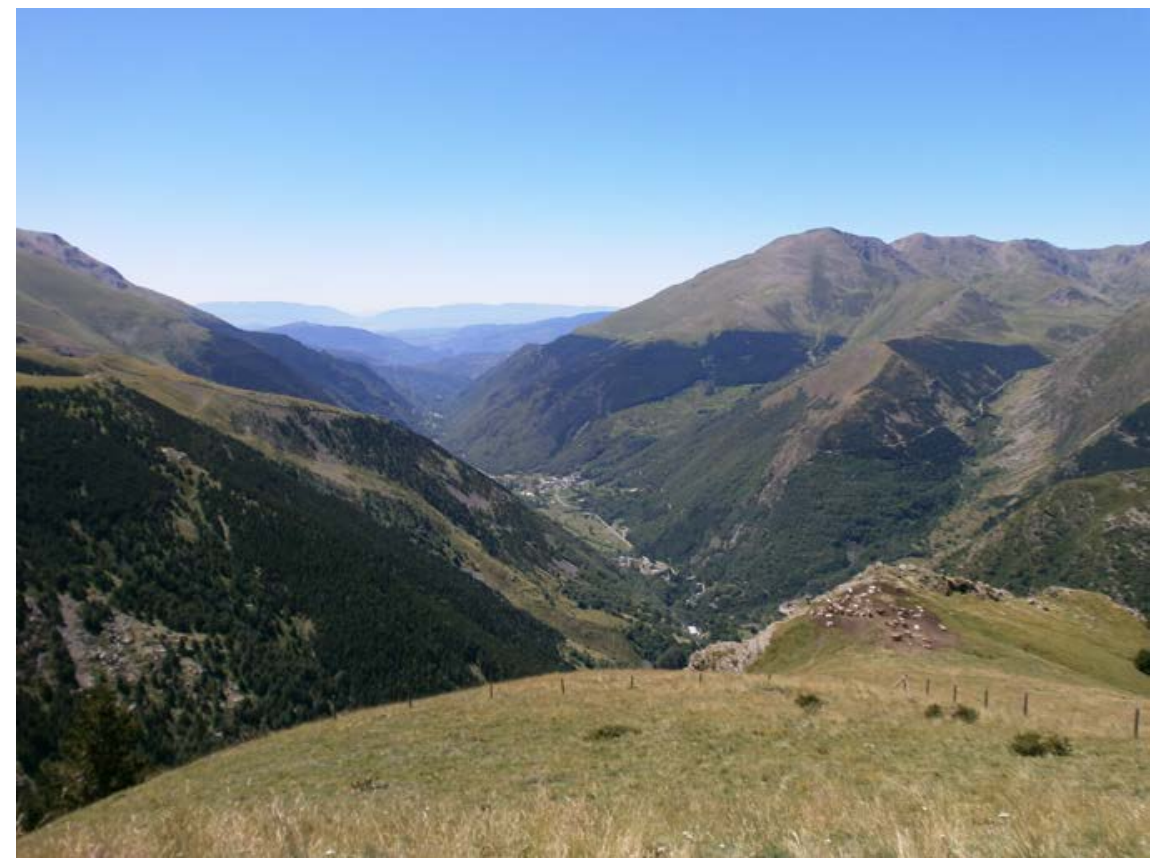

Fotografia 6. Un altre aspecte de la Vall Fosca, des de prop de la Pala de la Roda Pot observar-se l'aspecte glacial de la vall principal i de les vals penjades. Agost 2013 
També es poden veure des d'aquest indret, els relleus de la Pala de Polvoròs i del Pic de I'Espada, situats a ponent d'on ara som. Aquest relleus marcaven la divisoria entre el glacial que baixava de Sallente i el que baixaba del Coll de Rus, constituint les actuals Vall Fosca i Ribera de Riguerna, que s'ajunten prop de Cabdella. (fotografia 7).

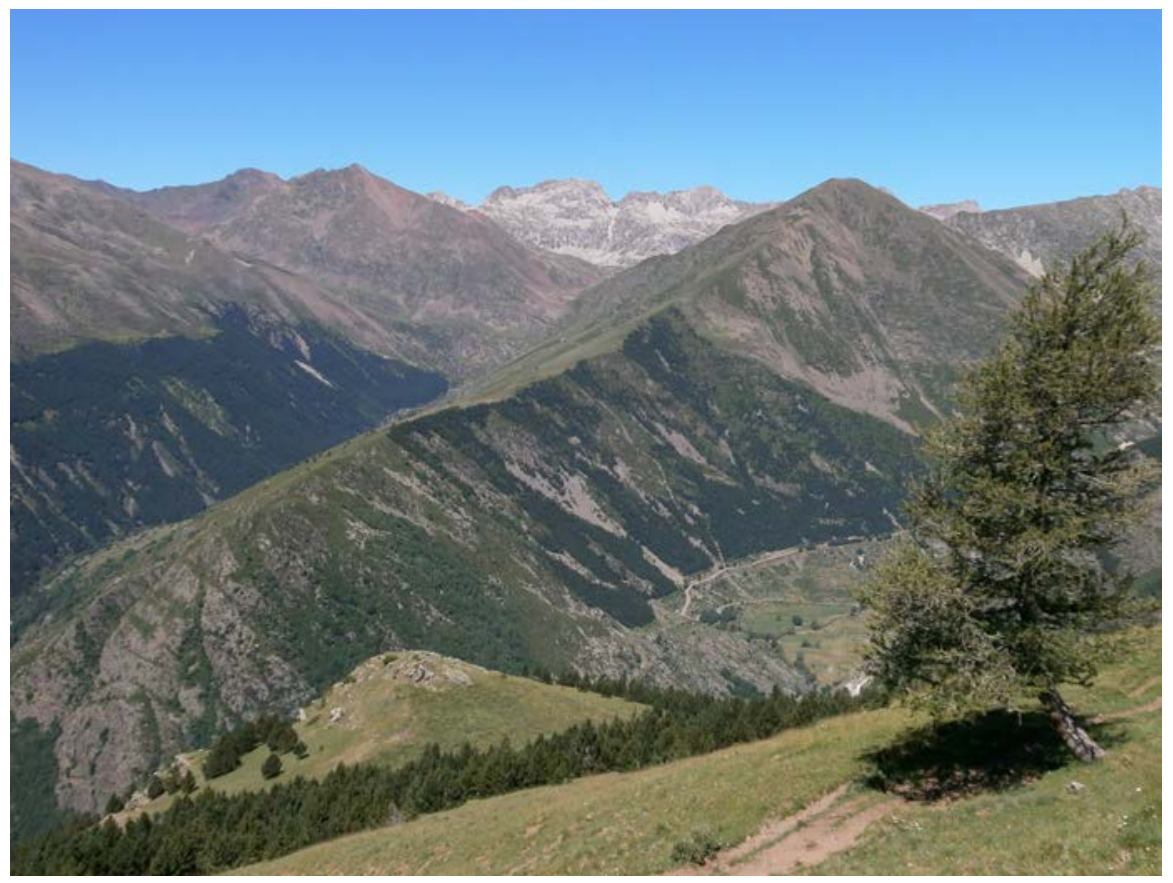

Fotografia 7. Un altre aspecte de la Pala de Polvoròs - Pic de I'Espada, separant la Vall Fosca i la Ribera de Riguerna. Era la divisoria que separava els dos glacials que baixaven per aquestes valls. Agost 2013

\subsection{Parada 8. VESSANT SEPTENTRIONAL DEL BARRANC DE VALLDOMARS, (Cabdella, terme municipal de la Torre de Cabdella, la Vall Fosca, comarca del Pallars Jussà). (Fulls 214 i 54).}

Des de realitzar l'aturada anterior, cal efectuar un breu recorregut, anant sempre cap el Nord, cap a l'Estany Gento. Tot i així, a uns 200 metres, podem fer una nova aturada, dintre d'aquest recorregut.

En aquest tram, hem continuat trobant afloraments dels materials paleozoics esmentats a les aturades anteriors. Així, sovint, haurem vist els nivells d'esquistos i de pissarres del Silurià. I més amunt, per sobre, es veuran els trams carbonatats del Devonià, els quals formen els relleus del Montsent del Pallars, situats a la nostra dreta, cap a llevant.

Malgrat això, molt sovint. Aquests materials del paleozoics que anem trobant i que formen l'Obaga del Montsent, es troben recoberts per materials de l'Holocè, formant part dels derrubis de pendent.

Xaragall.2014 n.8 | Modificacions al recorregut de recerca geològica i mineralògica per la comarca del Pallars Jussà: des d’Espui, cap al Coll de Triador, la Cambra d'Aigües, I’Estany Gento, I'Estany Tort i cap al Refugi de 
Sobre aquests materials, molt sovint s'han desenvolupats els típics fenòmens de solifluxió, Així, haurem trobat petits despreniments, moviments en massa, caminets de vaques. Això ha originat despreniments sobre la via, doblegament dels rails. Un exemple d'aquests fenòmens de solifluxió, es poden veure a la (fotografia 8).

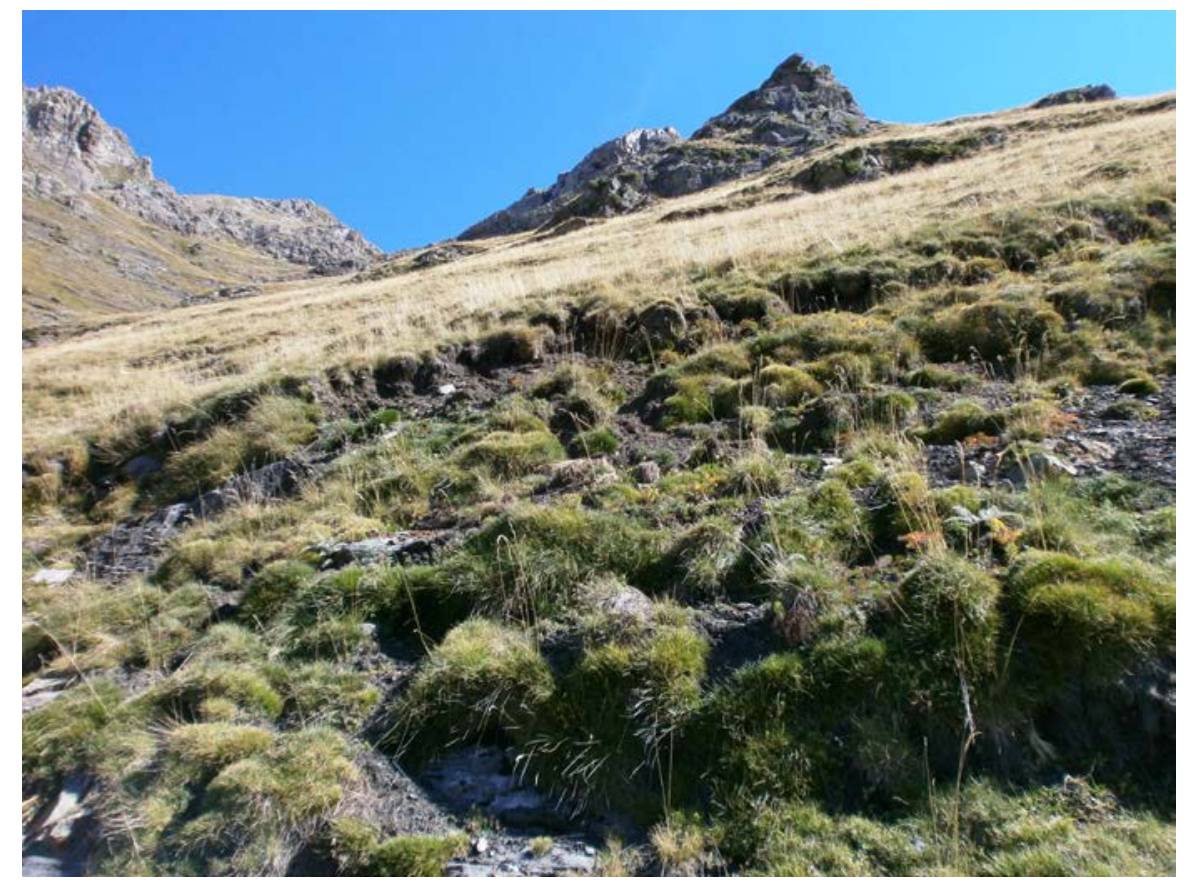

Fotografia 8. Un aspecte des fenòmens de solifluxió, a l’Aubaga del Montsent, per sobre del carrilet. Setembre 2013

\subsection{Parada 9. IMMEDIACIONS DEL CANAL DE PIGOLO, (Cabdella, terme municipal de la Torre de Cabdella, comarca del Pallars Jussà). (Fulls 181 i 54).}

Després de realitzar la parada anterior, cal continuar cap el Nord per la plataforma de l'antic ferrocarril, que es va apropant cap a l'Estany Gento. A poc més de $1^{\prime} 5 \mathrm{Km}$ de la parada anterior, per les immediacions del Canal de Pigolo, prop d'un dels túnels d'aquesta antiga via ferroviària.

En aquest recorregut, hem anat trobant afloraments dels materials pissarrencs del Silurià (les pissarres i esquistos, així com un nivell de quarsites), dels quals ja hem fet esment a l'aturada anterior, especialment dels primers. Tot i que sovint, haurem vist també afloraments dels nivells carbonatats del Devonià. Cal dir, que cada vegada més, estem entrant dintre de la Zona Axial Pirinenca. Per d'altra banda, també estem trobant afloraments del materials granítics i granodioritics carbonífers.

Tot i així, per arreu es fan palesos els recobriments dels materials anteriors, per part de depòsits neògens detrítics, generalment de procedència glacial, del Pleistocè i de l'Holocè. Aquests materials detrítics formen part de les morrenes glacials.

Xaragall.2014 n.8 | Modificacions al recorregut de recerca geològica i mineralògica per la comarca del Pallars Jussà: des d’Espui, cap al Coll de Triador, la Cambra d'Aigües, I’Estany Gento, I'Estany Tort i cap al Refugi de 
En aquest tram, sovint hem vist com les freqüents esllavissades, han deformat les antigues vies del ferrocarril que anem seguint. Tanmateix, hem passant al costat d'una antiga esllavissada, molt patent.

Pel que fa al carrilet, cal dir que aquest es va utilitzar per a la construcció de les preses situades més amunt. En el seu recorregut, aquest carrilet passa de la Unitat del Mantell de les Nogueres (on es troba la Cambra d'Aigües, prop d'Espui, per on començat a caminar) a la Zona Axial Pirinenca per on ens trobem ara situats. Aquest carrilet va constituir al seu moment una important obra d'enginyeria. (fotografies 9 i 10).

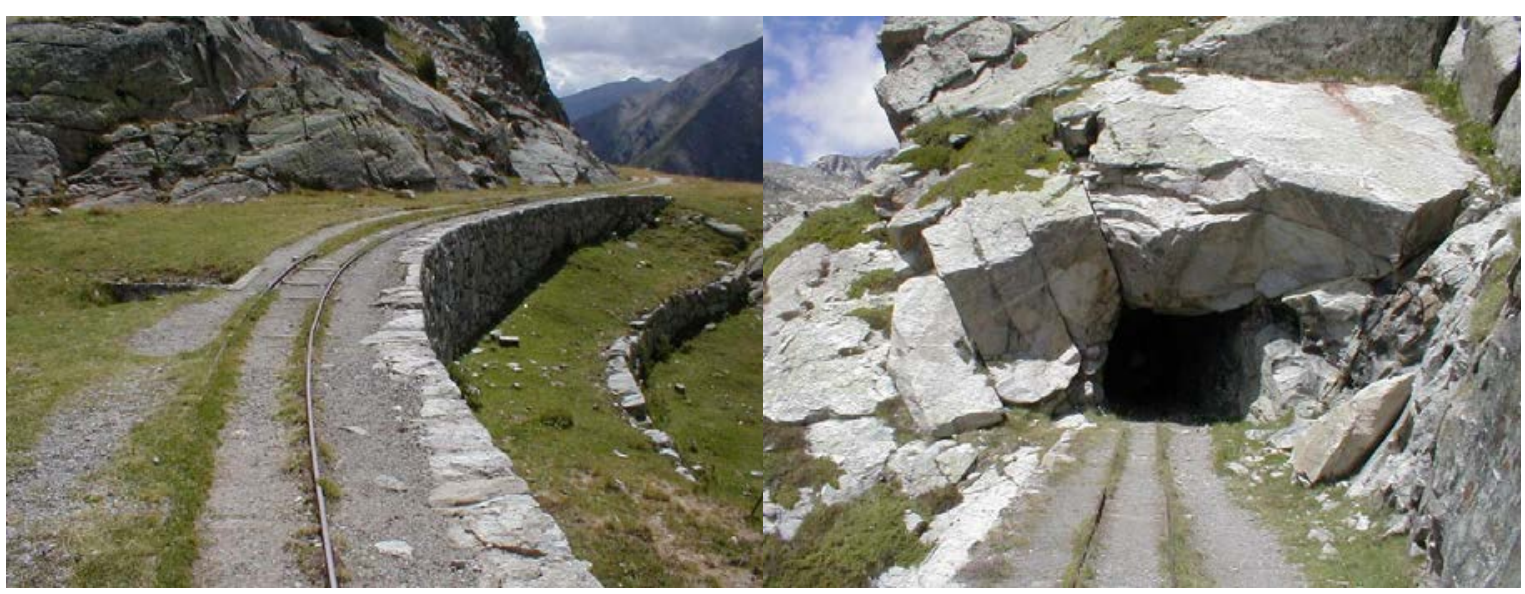

Fotografies 9 i 10. Dos dels trams del carrilet de I’Estany Gento. Agost del 2013 Al segon, es pot apreciar un túnel obert entre afloraments de granodiorites.

Des d'aquest indret es pot fer una primera observació de Sallente. En en aquest lloc hi ha un interessant embassament, construït sobre la vall del riu Sallente. Aquest embassament forma part del sistema hidràulic Estany Gento - Sallente. En efecte, aquí es recullen les aigües de diversos llacs d'origen glacial, destinats a l'obtenció d'energia hidroelèctrica. Al mateix temps, aquest és un llac reversible, de forma que periòdicament les aigües es bombegen cap a I'Estant Gento, situat més amunt, ja dintre del Parc Nacional d'Aigües Tortes - Sant Maurici. Aquest sistema, és un dels més importants de tot els Pirineus i de la Península Ibèrica.

Des de la via que condueix cap a l'Estan Gento, es pot fer una primera observació de I'Embassament de Sallente, així com de la pedrera d'on es van extreure part dels materials per la construcció de la pressa. (fotografies 11 i 12).

Xaragall.2014 n.8 | Modificacions al recorregut de recerca geològica i mineralògica per la comarca del Pallars Jussà: des d'Espui, cap al Coll de Triador, la Cambra d'Aigües, l'Estany Gento, I'Estany Tort i cap al Refugi de 


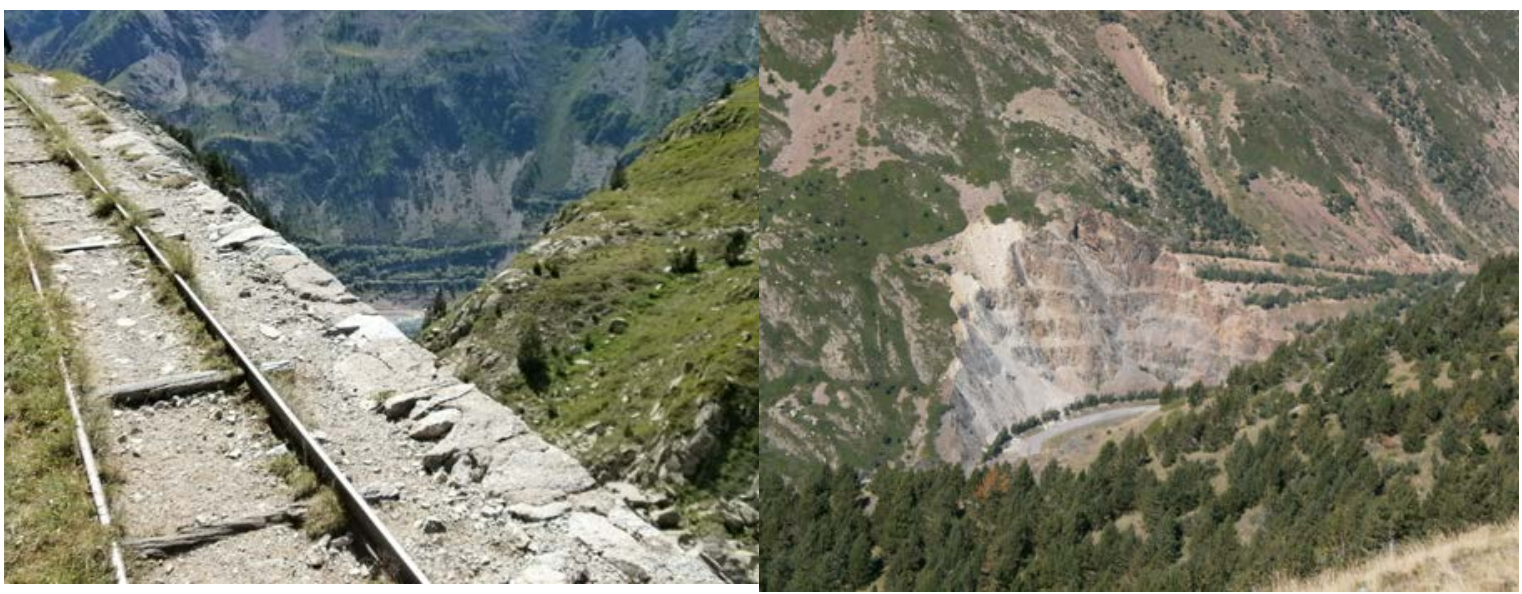

Fotografia 11. Un altre aspecte de la via del ferrocarril. Al fons es veu una petita part de l'Embassament de Sallente. Agost 2013.
Fotografia 12. Un altre aspecte de la pedrera de la qual es van extreu materials per a la construcció de la pressa de l'Embassament de Sallente. Setembre 2013.

També, des d'aquest indret, mirant cap a ponent, es pot veure el contacte entre els materials de l'Ordovicià (de l'altra vessant de la vall), amb els materials carbonífers. Amb les granodiorites i amb els granits. Aquest contacte, tot i que de canto, el podem veure ben marcat per les immediacions de la Colada de la Font Subirana. (fotografia 13).

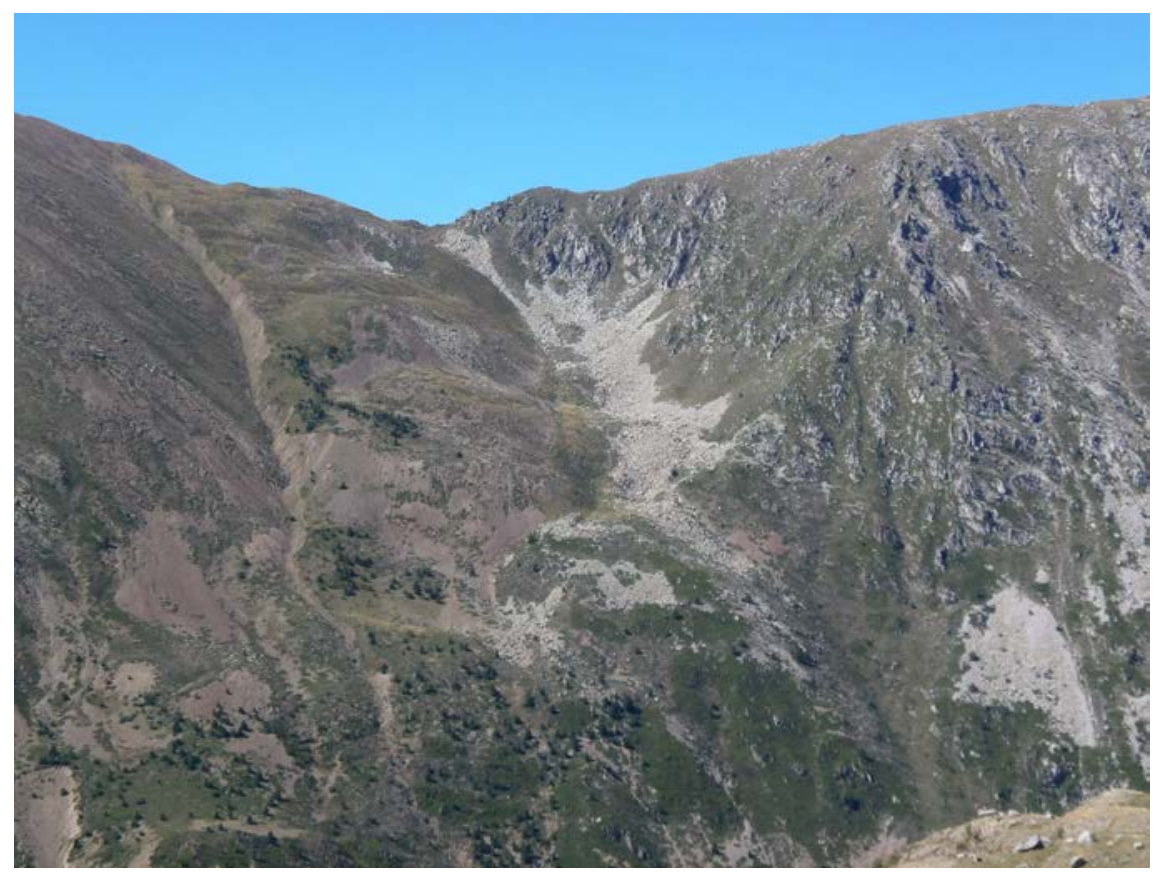

Fotografia 13. Contacte entre els materials de l'Ordovicià (nivells d'esquistos) i les roques ganítiques del Carbonífer a la Collada de la Font Subirana. Setembre 2013

Xaragall.2014 n.8 | Modificacions al recorregut de recerca geològica i mineralògica per la comarca del Pallars Jussà: des d’Espui, cap al Coll de Triador, la Cambra d'Aigües, I'Estany Gento, l'Estany Tort i cap al Refugi de 


\subsection{Parada 10. ESTANY GENTO, (Cabdella, terme municipal de la Torre de Cabdella, comarca del Pallars Jussà). (Fulls 181 i 54).}

Des de la parada anterior, cal continuar pel vial del ferrocarril, anant cap a l'Estany Gento. Així, hi arribarem en un nou recorregut, proper al $1^{\prime} 5 \mathrm{Km}$ des de la parada anterior. D'aquesta forma, haurem completat tot el recorregut d'aquest vial.

Com és evident, aquest recorregut, I'haurem fet. Íntegrament, per la Zona Axial Pirinenca. Així, haurem vist afloraments dels materials paleozoics esmentats a les aturades anteriors. Més amunt, haurem començat a trobar afloraments dels materials granítics (fonamentalment: granits i granodiorites). Aquests materials són els que apareixen pels voltants de I'Estany Gento, on estem ara situats. Així, per arreu es poden veure afloraments d'aquestes roques d'edat carbonífera, relaciones amb el plegament variscic (o hercinià).

L'Estany Gento, constitueix un dels principals llacs dels Pirineus de Catalunya. Te una clara morfologia glacial, formada pel soscavament de les glaceres sobre les roques granítiques acabades d'esmentar. Alhora, forma part de l'important complex lacustre de la Vall Fosca, format per nombrosos llacs, com els propers Estany Mar, Estany Colomina i Estany Tort, situats més amunt, entre molts altres que llacs i estanys donen les aigües al Noguera de Flamisell. (fotografia 14).

Precisament, totes les aigües dels llacs anteriors i les d'altres, de tot el complex lacustre de la Vall Fosca, són canalitzades cap l'embassament de Sallente, que hem vist a la parada anterior. Cal dir, que des del camí d'ascens cap a l'Estany Gento i des del mateix llac, es poden gaudir d'unes interessants vistes de l'Embassament de Sallente.

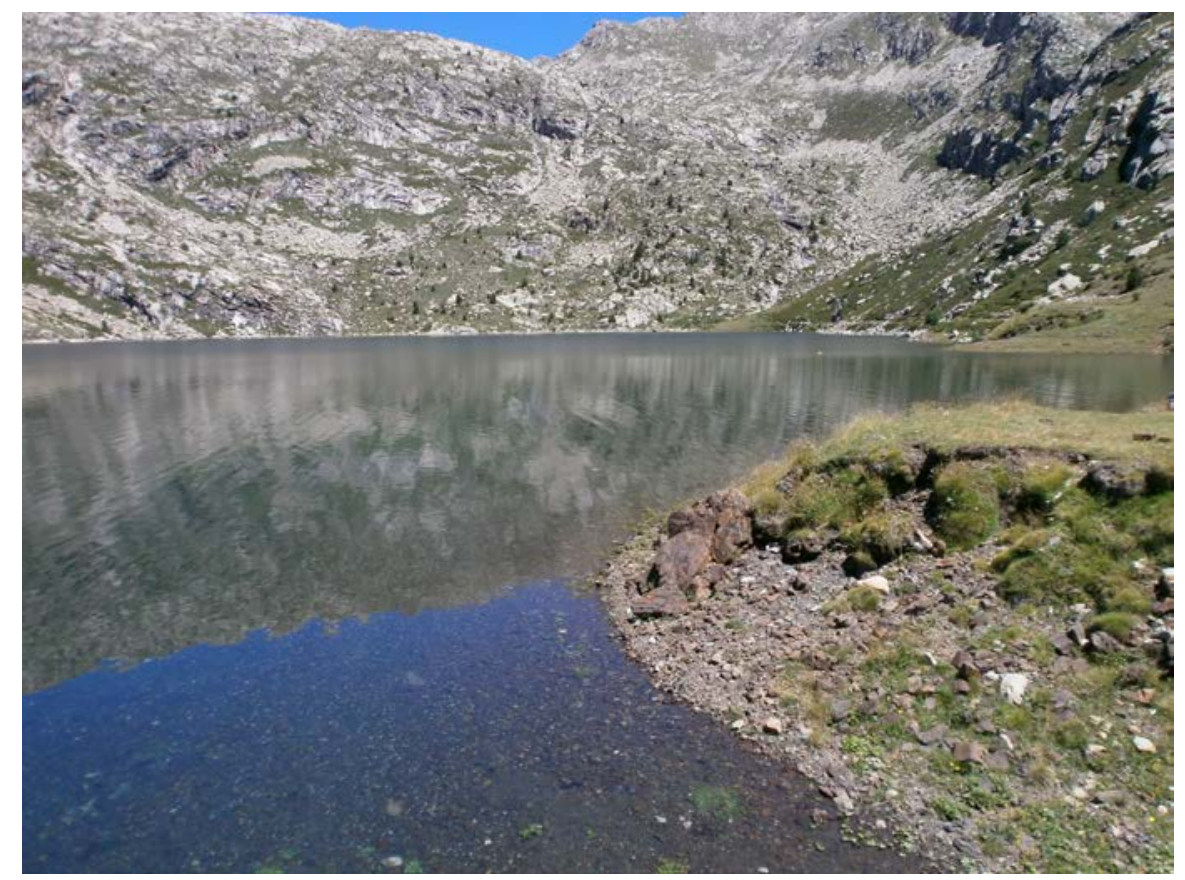

Fotografia 14. L’Estany Gento, entre afloraments de roques granítiques. Agost 2013

Xaragall.2014 n.8 | Modificacions al recorregut de recerca geològica i mineralògica per la comarca del Pallars Jussà: des d’Espui, cap al Coll de Triador, la Cambra d'Aigües, I’Estany Gento, I'Estany Tort i cap al Refugi de 
Cal dir, que poc abans d'arribar a aquest indret, haurem vist una important esllavissada, prop de la via, entre les granodiorites del Carbonífer. (fotografia 15).

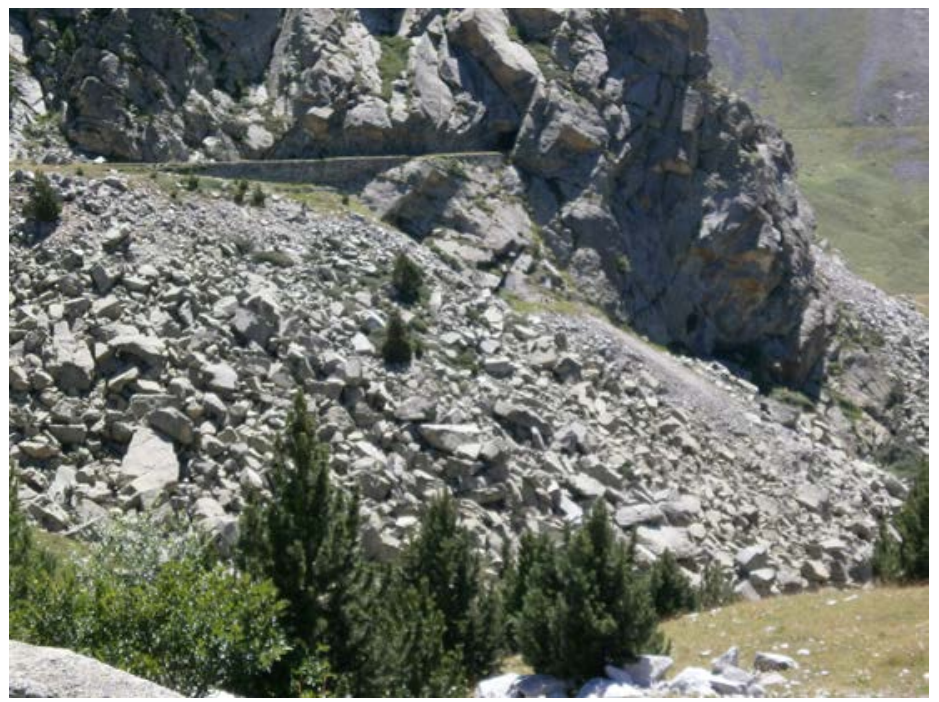

Fotografia 15. Un aspecte de l'esllavissada de les granodiorites, prop de l'Estany Gento. Agost 2013

També cal dir, que des del Refugi de l'Estany Gento (situat prop de I'Estació del Telefèric), es pot fer una bona observació de I'Embassament de Sallente, per sobre del qual ens trobem ara situats. (fotografia 16). Aquesta observació, es pot complementar amb la de les (fotografies 17 i 18).

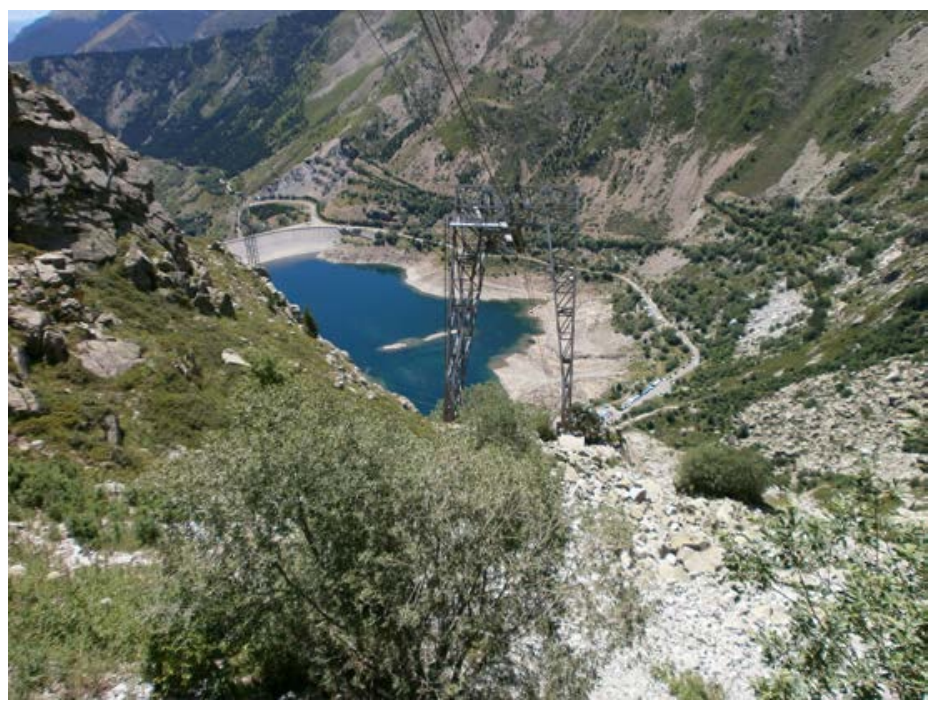

Fotografia 16. L'embassament de Sallente, vist des del Refugi de I'Estany Gento Al fons es veuren les roques grises metamòrfiques de I'Ordovicià i Cambro - Ordovicià Pel centre es fa palesa I'Aureola Metamòrfica I en primer terme es veuen les roques granítiques Agost 2013

Xaragall.2014 n.8 | Modificacions al recorregut de recerca geològica i mineralògica per la comarca del Pallars Jussà: des d'Espui, cap al Coll de Triador, la Cambra d'Aigües, I'Estany Gento, l'Estany Tort i cap al Refugi de 


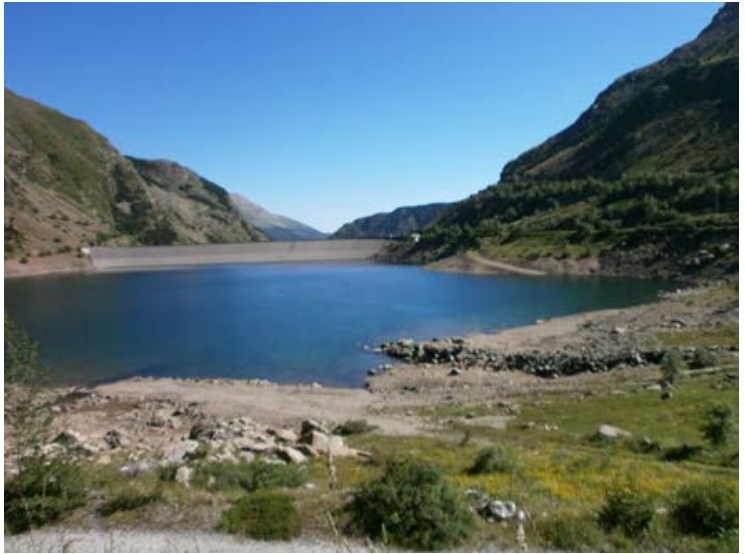

Fotografia 17. Un aspecte de l'embassament de Sallente Juliol 2013

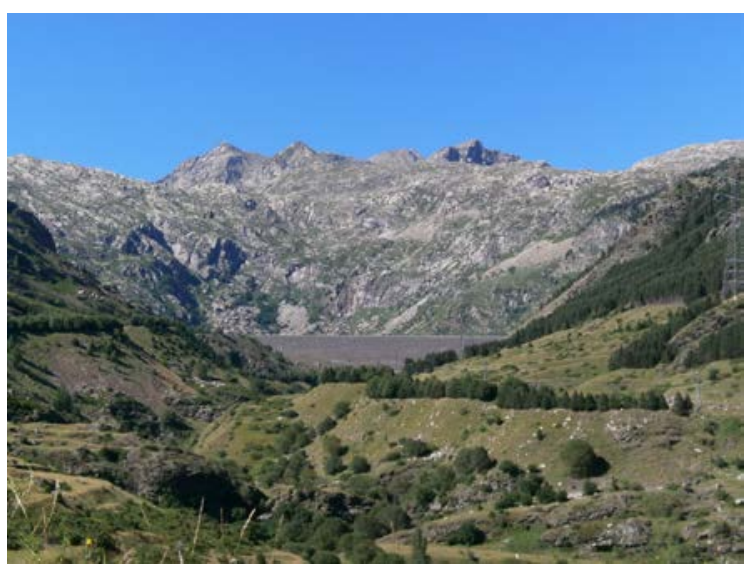

Fotografia 18. Aflorament dels granits, al sector septentrional de Sallente. Juliol 2013

Pel que fa a aquesta aturada, cal dir que prop del Refugi de I'Estan Gento, apareix un interessant contacte entre les roques granodiorítiques i els materials pissarrencs del Silurià. (fotografia 19).

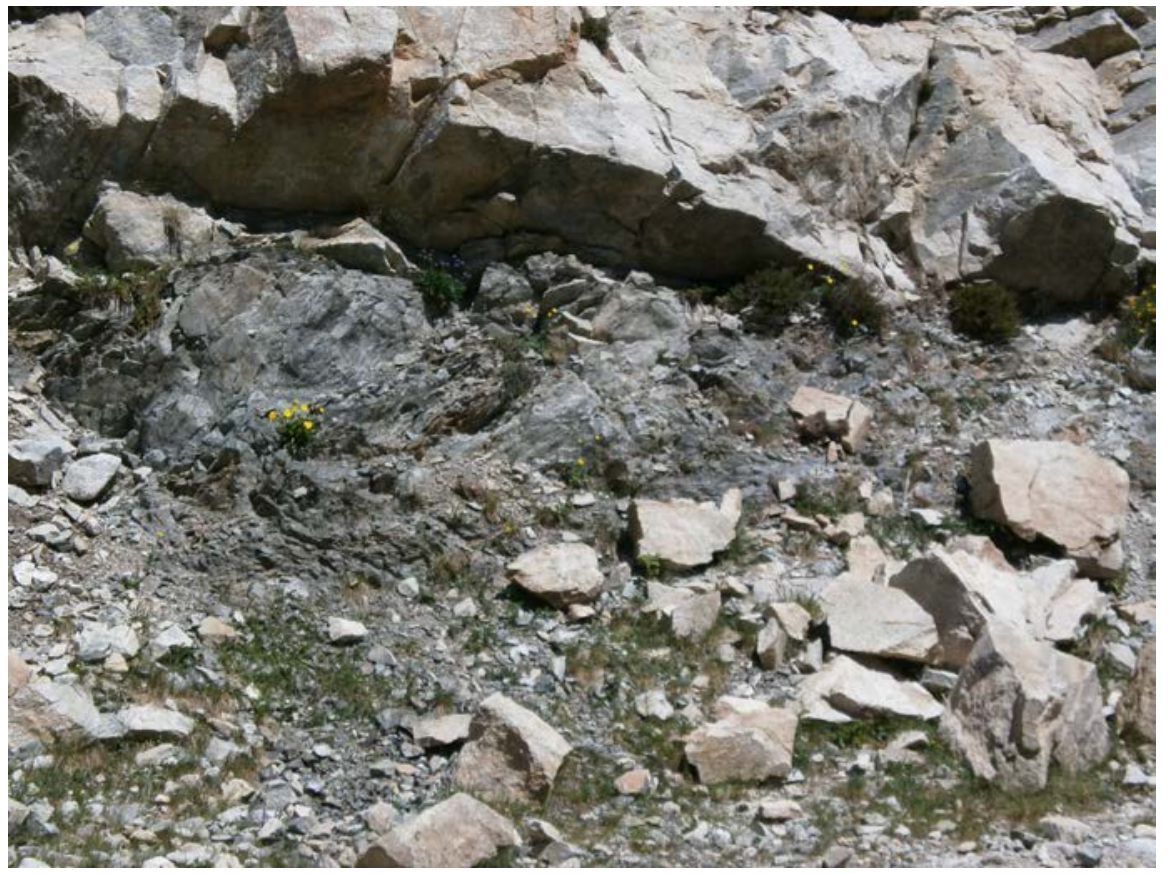

Fotografia 19. Contacte entre les granodiorites i els materials del Silurià. Al Refugi de l'Estany Gento. Agost 2013

Xaragall.2014 n.8 | Modificacions al recorregut de recerca geològica i mineralògica per la comarca del Pallars Jussà: des d'Espui, cap al Coll de Triador, la Cambra d'Aigües, l'Estany Gento, I'Estany Tort i cap al Refugi de 
I, finalment, mirant cap a llevant, es pot gaudir d'una bona visió del Montorroio, situat al Nord del Montsent de Pallars, per on afloren arreu els materials carbonatats del Devonià. (fotografia 20).

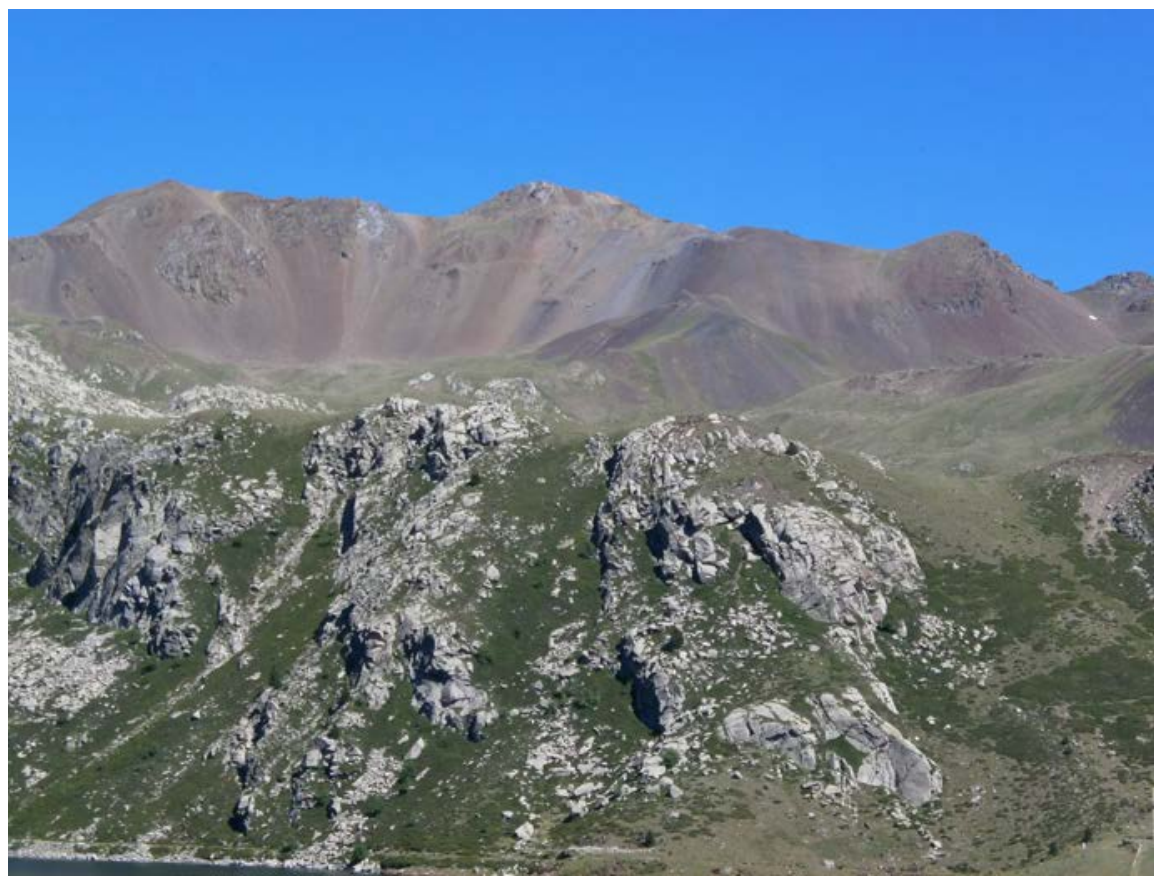

Fotografia 20. El Montorroio Aamb afloraments del Devonià).

En primer terme les granodiorites. Agost 2013

\subsection{Parada 11. CAMÍ DE PUJADA CAP A L'ESTANY TORT. LA PEDRA CABALLERA DE LA PORTELLA, (Cabdella, terme de la Torre de Cabdella, comarca del Pallars Jussà). (Fulls 181 i 54).}

Després de realitzar l'aturada anterior, cal continuar el recorregut a peu, pujant ara cap a I'Estany Tort. A mitja pujada, a quasi uns $15-20$ minuts de recorregut des del refugi de I'estany Gento, podem fer una nova aturada.

En aquest recorregut, hem continuat trobant afloraments dels materials granítics i granodiorítics del Carbonífer de la Zona Axial Pirinenca, on estem situats, Aquests són els materials que es troben a l'indret de la present aturada.

Aquí podem veure un interessant bloc de granodiorita en un equilibri lleugerament metaestable. Es tracta d'una pedra cabellera. (fotografia 21). 


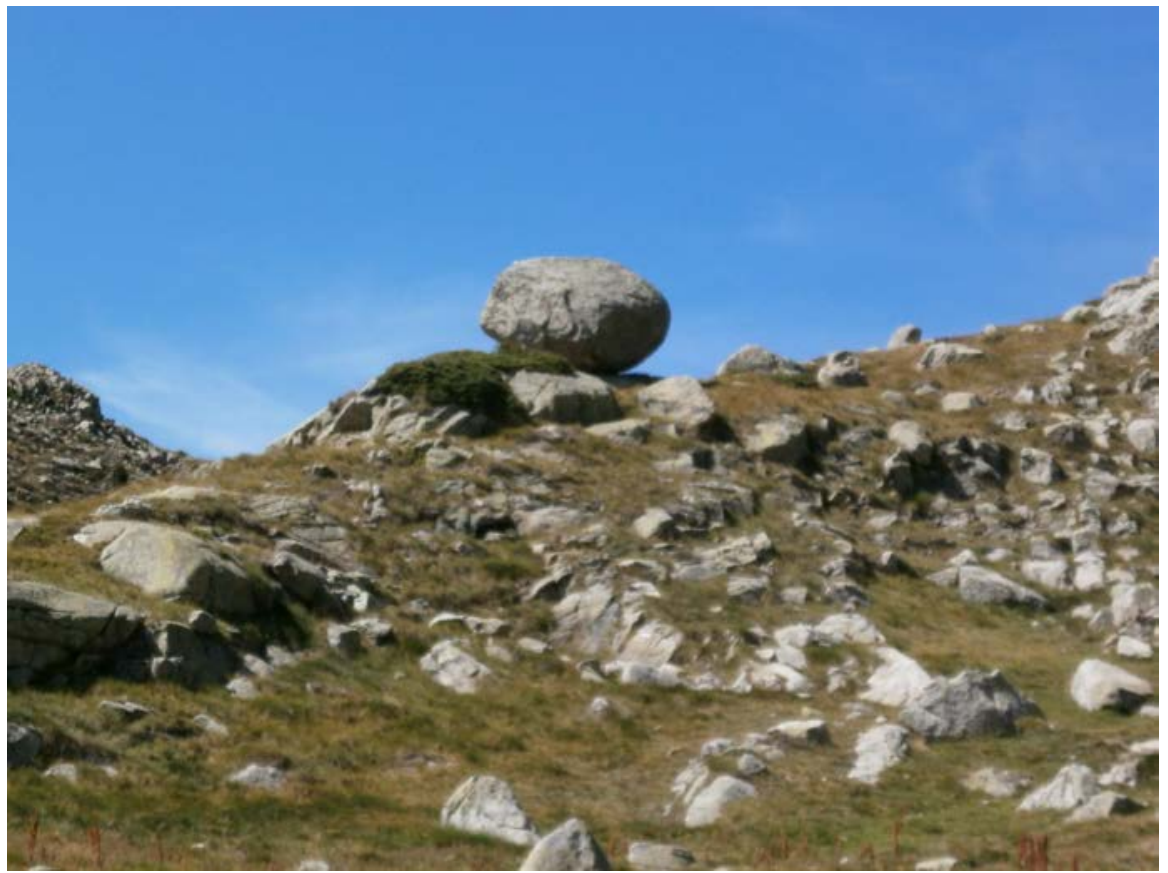

Fotografia 21. La pedra caballera de la Portella. Aflorament de roques granítiques del carbonífer, Setembre 2013

\subsection{Parada 12. ESTANY TORT, (Cabdella, terme de la Torre de Cabdella, comarca del Pallars Jussà). (Fulls 181 i 54).}

Després de realitzar l'aturada anterior, cal acabar d'arribar fins a l'Estany Tort. Abans trobarem la plataforma (i la via) d'un ferrocarril utilitzat per a la construcció de les presses als estanys. En arribar-hi, farem una nova aturada, aproximadament a uns 10 - 15 minuts de l'anteriorment efectuada, pujant.

En aquest nou recorregut, hem continuat trobant afloraments dels materials granítics esmentats a les aturades anteriors. Aquest són també els materials que apareixen a l'indret de la present aturada.

En aquest Iloc, hi ha un dels estanys més llargs de la Vall Fosca: es tracta de I'Estany Tort, per la seva forma. Abans, però, haurem trobat la via fèrria utilitzada als anys 20 del segle passat per les obres de captació d'aigües. Es tracta d'un interesant patrimoni miner, ja que aquestes obres van permetre l'aprofitament de les aigües, és a dir d'un dels materials geològics. (fotografia 22).

Xaragall.2014 n.8 | Modificacions al recorregut de recerca geològica i mineralògica per la comarca del Pallars Jussà: des d’Espui, cap al Coll de Triador, la Cambra d’Aigües, I’Estany Gento, I'Estany Tort i cap al Refugi de 


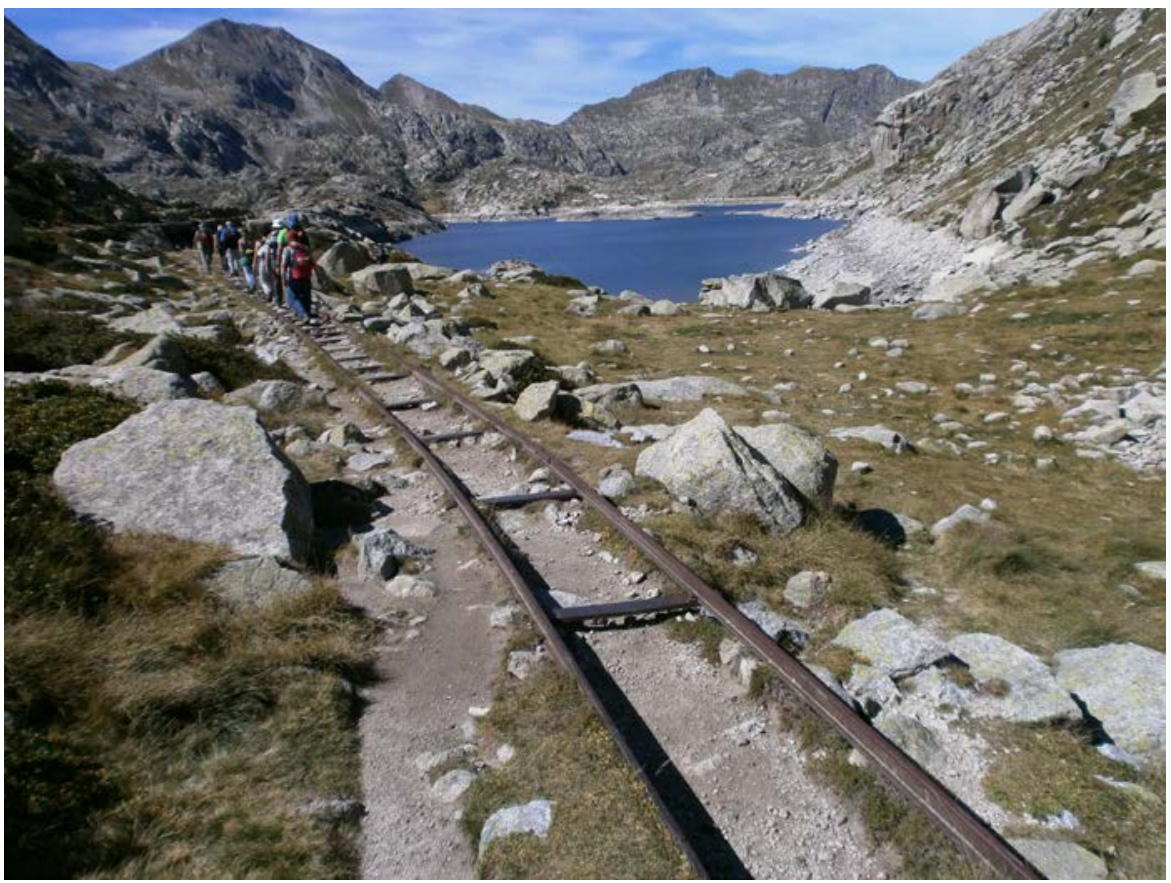

Fotografia 22. En primer terme el ferrocarril de l’Estany Tort. Al fons l'estany. Setembre 2013

\subsection{Parada 13. AIGUAMOLLS DE LA PORTELLA, (Cabdella, terme de la Torre de Cabdella, comarca del Pallars Jussà). (Fulls 181 i 54).}

Després de realitzar l'aturada anterior, cal recórrer lleugerament un tram del ferrocarril, per agafar immediatament després el camí cap a l'Estany Colomina. Poc després d'agafar aquest camí, podem fer una nova aturada, a uns 10 minuts de l'anterior.

En aquest recorregut, hem anat trobant afloraments dels materials esmentats a les aturades anteriors: els granits i granodiorites del Carbonífer.

Des d'aquest indret, mirant cap el sud, però sota d'on som ara i al costat de lla via fèrria, es poden veure uns interessants aiguamolls que corresponen a un antic llac mig dessecat. (fotografia 23).

Xaragall.2014 n.8 | Modificacions al recorregut de recerca geològica i mineralògica per la comarca del Pallars Jussà: des d’Espui, cap al Coll de Triador, la Cambra d'Aigües, I’Estany Gento, I'Estany Tort i cap al Refugi de 


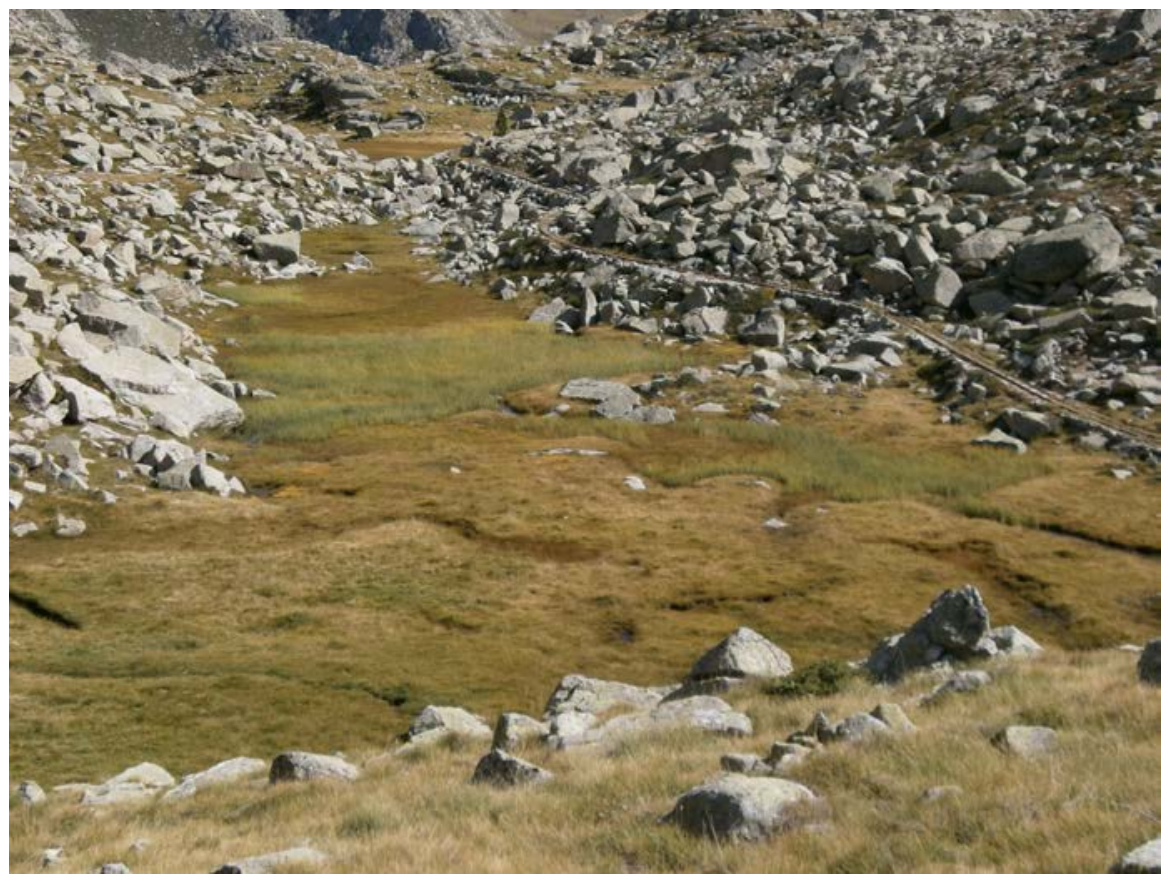

Fotografia 23. Als aiguamolls de la portella. Setembre 2013

\subsection{Parada 14. IMMEDIACIONS DEL REFUGI COLOMINA, (Cabdella, terme de la Torre de Cabdella, comarca del Pallars Jussà). (Fulls 181 i 54).}

Després de realitzar l'aturada anterior, si s'escau, pot efectuar-se un nou recorregut a peu, amb la finalitat d'arribar fins al Refugi Colomina, per on farem una nova aturada, després d'un recorregut proper als 10 minuts.

En aquest recorregut, realitzat totalment dintre de la Zona Axial Pirinenca, haurem continuat trobant afloraments de les roques granítiques que ja hem vist en el recorregut cap a l'aturada anterior. Així, en aquest tram, haurem també trobat, fonamentalment, les granodiorites del Carbonífer

Per d'altra banda, des d'aquest indret, es pot observar per arreu, la interessant morfologia glacial de la zona, com la que es veu a l'Estany Tort. Aquest estany el trobarem abans d'arribar a l'Estany de Colomina situat a tocar del refugi del mateix nom. FOTOGRAFIA 24.

Per d'altra banda, observant les roques granítiques, també es poden veure les empremtes del lliscament del glacial per sobre d'elles. (fotografia 25)..

Xaragall.2014 n.8 | Modificacions al recorregut de recerca geològica i mineralògica per la comarca del Pallars Jussà: des d'Espui, cap al Coll de Triador, la Cambra d'Aigües, l'Estany Gento, I'Estany Tort i cap al Refugi de 


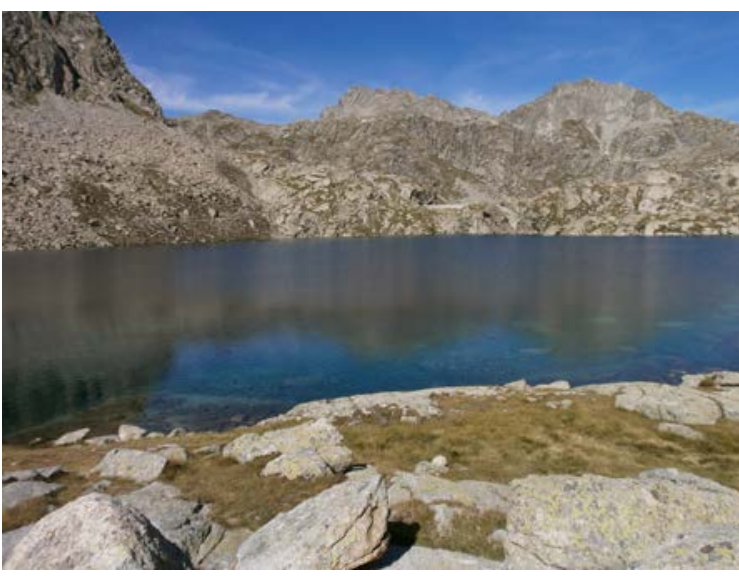

Fotografia24. L'Estany Colomina. Al fons es veu la pressa de I'Estany Mar. Setembre 2013

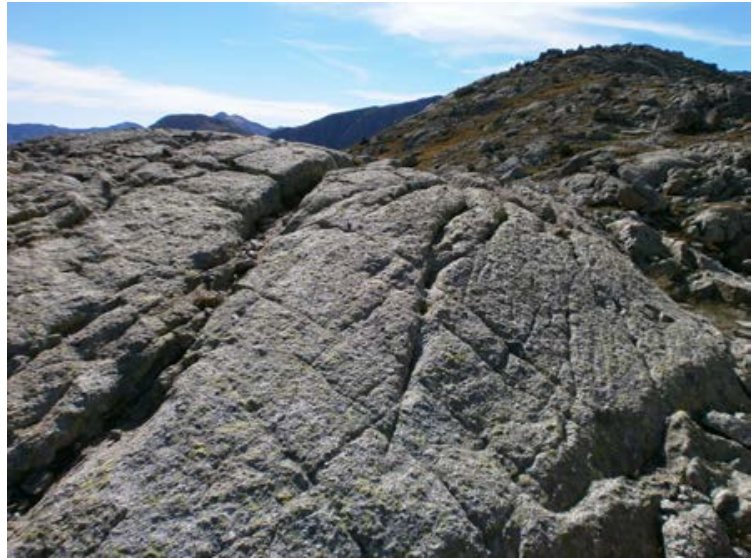

Fotografia 25. Estries del lliscament dels glacials sobre les roques granítiques. Setembre 2013

I finalment, mirant cap el Nord es pot veure la pressa de l'Estany Mar, situat més amunt de I'Estany Colomina, on estem ara.

En aquest indret finalitza el recorregut de l'itinerari.

\section{Bibliografia}

GUIMERÀ, J. et altri (1992).- Geologia (II), Història Natural dels Països Catalans, Vol. 2, 547 pag. Enciclopèdia Catalana, S.A. Barcelona.

IGME (1994).- Mapa Geológico de España a escala 1:50.000 (Plan Magna). Fulla i Memòria ${ }^{\circ}$ 252 (Tremp). Inst. GeoMinero y Tecnol. España. Minist. Indústria. Madrid.

MARTÍNEZ RIUS, A. Et altri (2013).- Guia Geològica del Parc Natural d’Aigüestortes i Estany de Sant Maurici. Publicada a Guies Geològiques dels Parcs Nacionals (dirigida per Roberto Rodríguez Fernández). IGME -Edit Everest. 225 pàgines. Madrid.

MATA-PERELLÓ, J.M. (1991).- Els Minerals de Catalunya. Arxius de la Secció de Ciències de I'Institut d'Estudis Catalans, vol.47, 545 pàgines. Barcelona.

MATA-PERELLÓ, J.M. (2013a).- Recorregut de recerca geològica i mineralògica per la comarca del Pallars Jussà: des de Senterada, a la Pobleta de Bellveí, a la Plana de Mont-ros, a Cabdella i a Sallente. Inèdit. 14 pàgines. Manresa.

MATA-PERELLÓ, J.M. (2013b).- Recorregut de recerca geològica i mineralògica per la comarca del Pallars Jussà: des de la Torre de Cabdella cap a Cabdella, Sallente i cap I'Estany Gento. Inèdit. 12 pàgines. Manresa.

MATA-PERELLÓ, J.M. (2013c).- Recorregut de recerca geològica i mineralògica per la comarca del Pallars Jussà: des d’Espui, cap al Coll de Triador, I'Estany Gento, I'Estany Tort i cap a Colomina. Inèdit. 14 pàgines. Manresa.

MATA-PERELLÓ, J.M. i SANZ BALAGUÉ, J. (1993).- Guía de identificación de Minerales, adaptada fundamentalmente a la Península Ibérica. Parcir, Edic. Selectas, 243 pàgines. Manresa.

Xaragall.2014 n.8 | Modificacions al recorregut de recerca geològica i mineralògica per la comarca del Pallars Jussà: des d’Espui, cap al Coll de Triador, la Cambra d'Aigües, I’Estany Gento, I'Estany Tort i cap al Refugi de 
RIBA ARDERIU, O. et altri (1976).- Geografia Física dels Països Catalans. Edit Ketres. 211 pàgines. Barcelona.

ROSELL SANUI, J. (1970).- Explicació del Mapa Geològic, a escala 1:50.000, corresponent al full nº 252 (Tremp). Mapa Geológico de España. Inst. Geológico y Minero de España. Madrid. 